\title{
The effect of ingestion of guar gum on ileostomy effluent
}

\author{
BY S. E. HIGHAM AND N. W. READ \\ Centre for Human Nutrition, The University of Sheffield, Northern General Hospital, \\ Herries Road, Sheffield S5 7 AU
}

(Received 27 June 1990-Accepted 25 March 1991)

\begin{abstract}
Randomized, paired studies were carried out on five healthy volunteers equipped with terminal ileostomies to investigate the effect of incorporating $15 \mathrm{~g}$ of the viscous polysaccharide guar gum in the normal diet on the volume, weight, composition and physical properties of ileostomy effluent. Subjects ate an identical diet during two $5 \mathrm{~d}$ study periods, which were separated by $2 \mathrm{~d}$. Outputs of fat, protein, sodium, potassium, dry weight and water were all increased during guar gum administration, but outputs of carbohydrate, calcium and phosphorus were not significantly altered. Mouth-to-stoma transit was not significantly affected and, surprisingly, the viscosity of the ileostomy effluent was reduced by guar gum. These results show that it is not always possible to predict what will happen to small intestinal function when guar gum is added to the diet from experiments carried out when guar gum is administered alone or with glucose. While our findings show that guar gum will reduce fat absorption, the mechanisms involved are more sophisticated than hitherto envisaged.
\end{abstract}

Guar gum: Ileostomy effluent

Guar gum is a high-molecular-weight galactomannan produced from the cluster bean, Cyamopsis tetragonoloba. This polysaccharide cannot be digested in the mammalian small intestine and forms viscous solutions which are thought to delay the absorption of other components of the diet (Blackburn et al. 1984) and so reduce post-prandial plasma levels of glucose and cholesterol (Smith \& Holm, 1982; Fuessl et al. 1987).

We have previously suggested that the reduced absorption of nutrients produced by guar gum is probably a direct consequence of the increased viscosity of gastrointestinal contents (Blackburn et al. 1984) which slow the delivery from the stomach to the small intestine, impair the mixing of substrate with digestive enzymes and reduce the rate of contact of nutrients with the absorptive epithelium (Read, 1986).

If absorption is impaired sufficiently, it could mean that a large proportion of nutrients escape absorption in the small intestine and pass into the colon where their absorption may be incomplete and the energy yield to the host reduced (McNeil, 1984). These effects may be partially compensated by an increase in small bowel transit time (Read, 1986), which would be expected to increase the amount absorbed by enhancing the residence of nutrients in the small intestine. Thus, it is difficult to predict the effect of guar gum on nutrient availability and no previous studies have addressed this question in man.

In dogs, the addition of guar gum to a meal increases the weight of chyme at mid small intestine and reduces the absorption of fat (Meyer \& Doty, 1988). In another study, jejunal transit was slowed after ingestion of guar gum but the flow was increased, indicating a greater intestinal volume (Bueno et al. 1981).

The aim of the present study was to gain some insight into the effect of guar gum on the degree of absorption in the human small intestine by measuring how the volume, 
composition and physical properties of ileal effluent are altered by adding guar gum to the usual diet of ileostomy patients.

\section{METHOD \\ Subjects}

Studies were carried out on five healthy subjects, four women and one man, aged between 48 and 70 years, who had ileostomies constructed from the end of the small intestine with less than $100 \mathrm{~mm}$ of the terminal ileum resected. The operations were carried out more than 2 years before the study. Four of the subjects had been treated for ulcerative colitis and one for Crohn's colitis. The latter had had no disease in the small intestine and the total excretion of the ileostomy effluent and its nutrient content were in the same range as that of the other patients. Only one patient was taking medication (anticonvulsants) and the same quantities were taken during both study periods. All had given their informed consent for the study to be carried out.

All the subjects had carried out similar studies previously and had proved to be reliable and conscientious.

\section{Protocol}

Each subject ate their own normal diet which included three main meals daily (plus any snacks) for a period of $5 \mathrm{~d}$. A careful, detailed record was made of the type and quantity of food and drink taken throughout each day. After a $2 \mathrm{~d}$ gap during which the patient was allowed to eat ad lib., an identical diet was eaten over a second $5 \mathrm{~d}$ period the following week. Water and other drinks were carefully monitored to ensure an equal intake was consumed during both periods. The diet records were analysed to calculate the daily nutrient and energy intakes during the two periods. One sachet of guar gum ( $5 \mathrm{~g}$; Rybar Laboratories Ltd, Amersham, Bucks,) was taken with meals three times daily during one of the $5 \mathrm{~d}$ periods. The order was randomized. Fifty radio-opaque plastic markers (segments of polyvinyl tubing: $4 \mathrm{~mm} \times 2 \mathrm{~mm}$ ) were eaten with breakfast on day 4 of both study periods to enable the transit times to be estimated.

All ileostomy effluent was collected throughout the studies. The overnight sample on the morning of day 1 was discarded; thereafter the ileostomy bag was checked hourly and every sample was transferred to a preweighed plastic pot which was chilled immediately before being deep frozen to $-20^{\circ}$. Collections were continued to include the overnight sample on day 5 .

Only the samples from the final $3 \mathrm{~d}$ of each period were analysed. Individual samples of ileostomy effluent were first weighed, X-rayed to determine marker numbers, and then subjected to physical and chemical analyses.

\section{Viscosity}

The 'apparent' viscosity of ileostomy samples was estimated using a rotary viscometer (Brookfield viscometer model LVT DV-II fitted with a Helipath stand; Brookfield, Stoughton, MA, USA). All the samples exhibited non-Newtonian behaviour; in this case it was shear thinning. Thus, in order to obtain comparable results, all estimations were made under standardized conditions $\left(25^{\circ}, 1.5\right.$ rotations $/ \mathrm{min}$ using a $t$ bar with cross bar $15 \mathrm{~mm}$ long; Ellis et al. 1986).

\section{Chemical analysis}

All samples collected over each $24 \mathrm{~h}$ period were pooled and homogenized with $1 \mathrm{~g}$ Thimerosal (sodium methylmercurithiosalicylate; Sigma Chemical Co. Ltd, Poole, Dorset) to minimize bacterial decomposition. Portions of $25 \mathrm{~g}$ were taken for fat analysis and the 

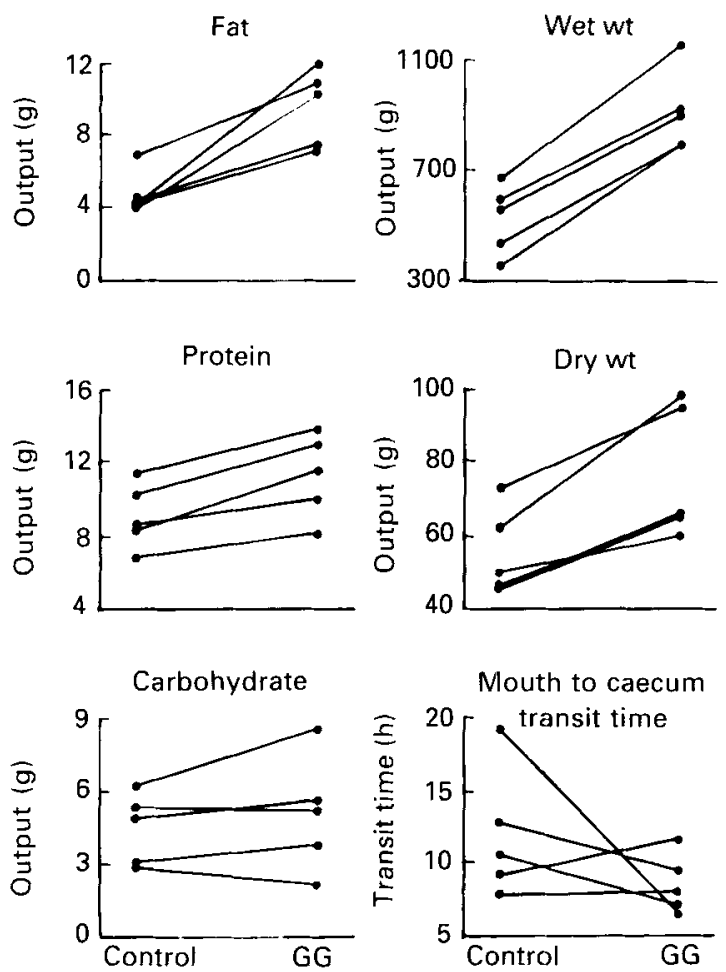

Fig. 1. The mean daily ileostomy outputs and mouth-to-stoma-transit times in five subjects with and without dietary additions of guar gum (GG) (for details of protocol, see p. 116).

remainder was poured into shallow preweighed trays and freeze-dried to constant weight (Edwards EF4 Modulyo freeze drier, attached to an Edwards high vacuum pump, model E2 M5; Edwards, Crawley, West Sussex).

The details of methods of analysis for the nutrients have been described previously (Higham \& Read, 1990). Dietary starch plus sugar was hydrolysed by boiling in 1 mol sulphuric acid and the glucose released was assayed using the GM6 glucose analyser (Analox Instruments Ltd, Brackenbury Road, Hammersmith, London). Protein was determined by the Kjeldahl-Nesslerization method and fat by an adaptation of the Van de Kamer method (Van de Kamer et al. 1949). Samples were ashed and dissolved in trichloroacetic acid $(200 \mathrm{~g} / \mathrm{l})$ in preparation for measurement of mineral content (Varley, 1984). Analysis of sodium and potassium was carried out using a Corning 435 flame photometer (Corning, Medfield, MA, USA). Atomic absorption spectrophotometry was used to determine calcium concentrations (Model 460; Perkin Elmer, Beaconsfield, Bucks.), and total phosphorus was determined by the phosphomolybdate reduction method (Varley, 1984). The $\mathrm{Na}, \mathrm{K}, \mathrm{Ca}$ and $\mathrm{P}$ contents of the guar-gum granules were also measured. The small amounts found were subtracted from the mineral content of the effluent.

\section{Mouth-to-stoma transit times}

Transit times were determined by estimating the time taken for the delivery of $50 \%$ of the solid markers in the ileostomy effluent. In a previous study the ileostomy deliveries of liquid and solid markers added to the same meal were found to be virtually identical (Higham \& Read, 1990). 
Table 1. Effect of ingestion of guar gum on ileostomy effluent $(/ 24 \mathrm{~h})$ and transit time in human subjects

(Mean values with their standard errors)

\begin{tabular}{|c|c|c|c|c|}
\hline \multirow[t]{2}{*}{ Treatment group $\dagger \ldots$} & \multicolumn{2}{|c|}{ Control } & \multicolumn{2}{|c|}{ Guar gum } \\
\hline & Mean & SEM & Mean & SEM \\
\hline Transit time (h) & 11.89 & $2 \cdot 00$ & $8 \cdot 60$ & 0.94 \\
\hline Wet wt (g) & 526.9 & $39 \cdot 6$ & $907 \cdot 1^{*}$ & $42 \cdot 6$ \\
\hline Dry wt $(\mathrm{g})$ & $55 \cdot 80$ & $3 \cdot 37$ & $77 \cdot 58^{*}$ & 5.06 \\
\hline Water $(\mathrm{g})$ & $476 \cdot 1$ & $35 \cdot 1$ & $846 \cdot 0^{*}$ & 38.5 \\
\hline Fat $(\mathrm{g})$ & $4 \cdot 80$ & 0.47 & $9 \cdot 36^{*}$ & 0.70 \\
\hline Protein $(\mathrm{g})$ & $9 \cdot 10$ & 0.64 & $11 \cdot 40^{*}$ & 0.70 \\
\hline Carbohydrate (g) & $4 \cdot 50$ & $0 \cdot 44$ & $5 \cdot 07$ & 0.71 \\
\hline Sodium (mM) & $60 \cdot 69$ & $4 \cdot 49$ & $103.45^{*}$ & 6.49 \\
\hline Potassium (mM) & $6 \cdot 23$ & $0 \cdot 99$ & $13 \cdot 73^{*}$ & $2 \cdot 18$ \\
\hline Calcium (mM) & $16 \cdot 54$ & 1.48 & $15 \cdot 88$ & $1 \cdot 40$ \\
\hline Phosphorus (mM) & $8 \cdot 58$ & $0 \cdot 74$ & $8 \cdot 25$ & 0.74 \\
\hline
\end{tabular}

Mean values were significantly different from control values: ${ }^{*} P<0.01$

$\dagger$ For details, see p. 116 .

\section{Statistical analysis}

The results are expressed as means with their standard errors for fifteen samples. The differences in the transit times, weights and nutrient outputs in the two study periods were assessed using a Student's paired $t$ test. Because viscosity varied from sample to sample over a wide range, the results over the $3 \mathrm{~d}$ periods were converted to logarithms and integrated with relative volume to obtain a single value, referred to as the viscosity index. Values from the two study periods were then compared using the Mann Whitney $U$ test.

\section{RESULTS}

The ileostomy bag was emptied more frequently while subjects were ingesting guar gum (guar gum 7.1 (SE 0.5) v. control $5.1($ SE 0.3$) / \mathrm{d}, P<0.001)$ and all patients produced much more ileal effluent on guar gum (Fig. 1 and Table 1). This comprised increases in both dry weight and free water. The water content also increased from a mean of $891 \mathrm{~g} / \mathrm{kg}$ during the control period to $915 \mathrm{~g} / \mathrm{kg}$ during the guar-gum period $(P<0.002)$.

\section{Nutrient intake}

The daily intake of protein, fat, carbohydrate and the energy content of the food during the two study periods were not significantly different (Table 2).

\section{Nutrient output}

The outputs of both fat and protein were increased on guar gum; in fact the fat excretion was doubled (Table 1 and Fig. 1). Dietary starch plus sugar output was not significantly changed (Table 1). Na and $\mathrm{K}$ outputs were increased, but $\mathrm{Ca}$ and $\mathrm{P}$ outputs were unaffected by guar gum administration (Table 1 and Fig. 2).

\section{Transit time}

Mouth-to-stoma transit time varied from 7.8 to $19 \cdot 2 \mathrm{~h}$ during the control period and between 6.5 and $11.7 \mathrm{~h}$ during the guar-gum period. This suggested a more rapid transit with guar gum, but the differences between the two periods were not significant $(P>0 \cdot 05$; Table 1 and Fig. 1). 

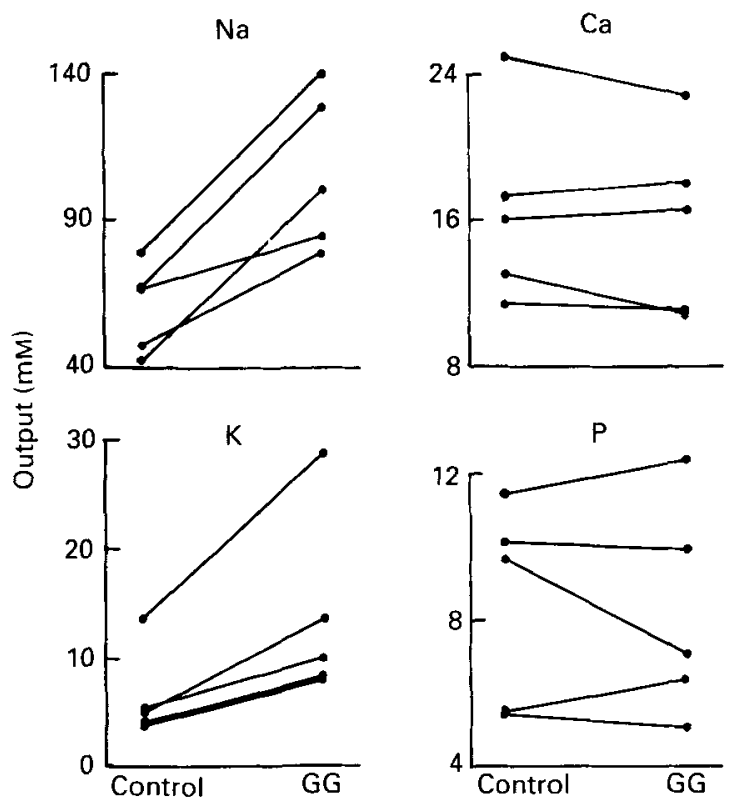

Fig. 2. The mean daily ileostomy outputs of sodium, potassium, calcium and phosphorus of five subjects with and without dietary addition of guar gum (GG) (for details of protocol, see p. 116).

Table 2. Effect of the addition of guar gum to the diet on daily energy and nutrient intake (Mean values with their standard errors)

\begin{tabular}{|c|c|c|c|c|}
\hline \multirow[t]{2}{*}{ Treatment group $\dagger \ldots$} & \multicolumn{2}{|c|}{ Control } & \multicolumn{2}{|c|}{ Guar gum } \\
\hline & Mean & SEM & Mean & SEM \\
\hline Protein $(\mathrm{g} / \mathrm{d})$ & $86 \cdot 8$ & $4 \cdot 7$ & $86 \cdot 1$ & $5 \cdot 1$ \\
\hline Fat $(g / d)$ & $83 \cdot 0$ & 8.9 & $78 \cdot 2$ & $9 \cdot 6$ \\
\hline Carbohydrate $(\mathrm{g} / \mathrm{d})$ & $274 \cdot 6$ & $14 \cdot 1$ & $276 \cdot 4$ & $15 \cdot 2$ \\
\hline Energy $(\mathrm{MJ} / \mathrm{d})$ & 8.88 & 0.54 & 8.72 & 0.61 \\
\hline
\end{tabular}

$\uparrow$ For details, see p. 116.

Viscosity

Administration of guar gum produced a highly significant reduction in the viscosity of the ileostomy effluent, $(P<0.001 ;$ Fig. 3$)$ The viscosity values were generally within a narrower range during guar gum administration and there were no samples with viscosities higher than $650000 \mathrm{cp}$. Many samples had much higher viscosities than this during the control period. The viscosities of all samples of ileostomy effluent for a typical patient over a $3 \mathrm{~d}$ period are shown in Fig. 4.

\section{DISCUSSION}

The results of the present study show that incorporating guar gum into a normal diet can increase losses of water, fat, protein and $\mathrm{Na}$ from the terminal ileum, without any discernible change in food intake. Since insignificant amounts of energy are provided from degradation of protein in the colon and dietary fat is converted to unabsorbable soaps (McNeil, 1984), our results support the contention that, in the short term, ingestion of guar 


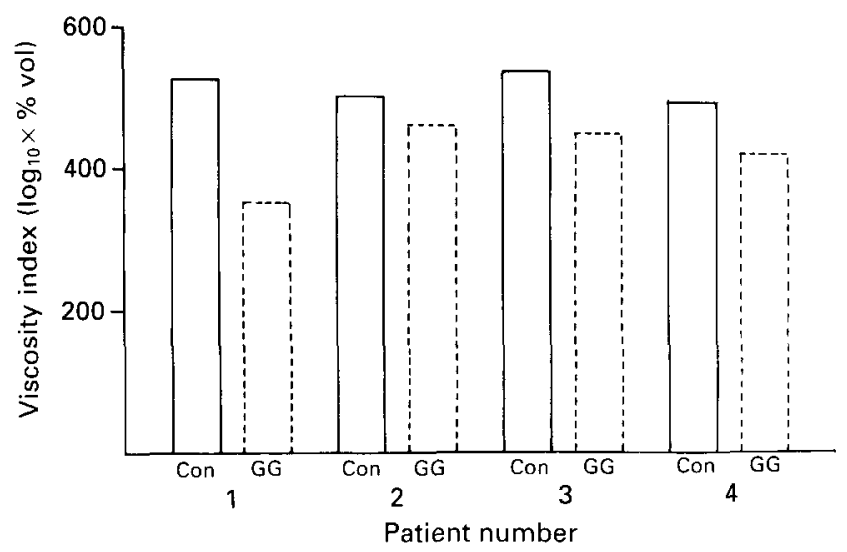

Fig. 3. The integrated viscosity (the viscosity $(\mathrm{cp})\left(\log _{10}\right)$ integrated with the relative volume) in four subjects are shown during $3 \mathrm{~d}$ control (con) period $(-)$, and $3 \mathrm{~d}$ on guar gum (GG) $(--)$ ). For details of protocol, see p. 116.

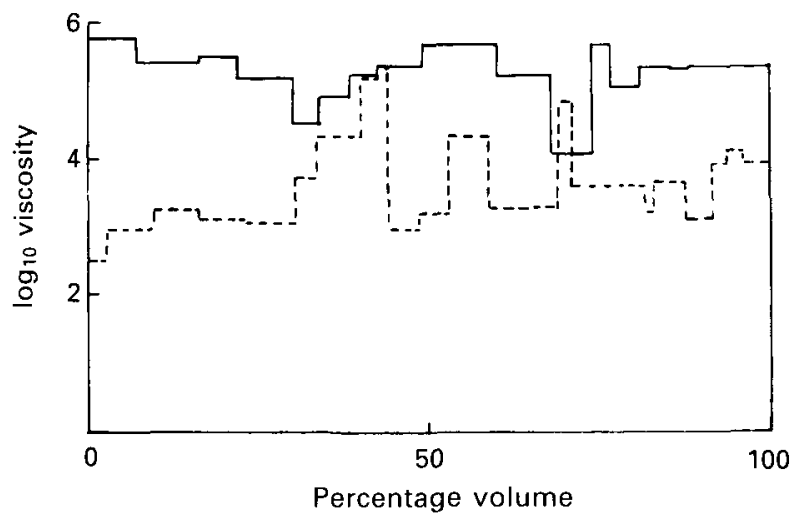

Fig. 4. Log viscosity of the ileostomy effluent collected over $3 \mathrm{~d}$ periods expressed in relation to the volume of each sample, $((\quad)$, control; (---), guar gum) for a typical subject (for details of protocol, see p. 116).

gum could reduce nutrient intake and contribute to weight loss (Evans \& Miller, 1975). Another viscous polysaccharide, citrus pectin increased ileostomy output of nitrogen, fat, $\mathrm{Na}, \mathrm{K}$ and wet and dry weights (Sandberg et al. 1983).

The increases in ileostomy output could either be due to an increase in digestive secretions or a decrease in absorption, or both. Studies carried out in experimental animals have suggested that ingestion of viscous polysaccharides may increase output of pancreatic juice (Sommer \& Kasper, 1980), which would account for the increases in protein, salt and water outputs. Viscous polysaccharides have also been shown to increase the output of biliary lipids in faeces (Adrian, 1976); such losses would make only a very small contribution to our observed increase in fat output. Thus, it seems more likely that the increases in fat content of the ileostomy effluent during ingestion of guar gum are caused by impaired absorption.

There is no evidence that guar gum would have any direct chemical action on absorption across the epithelium. Instead it seems reasonable to assume that guar gum reduces absorption by increasing the viscosity of lumen contents which would, in turn, impair the mixing of chyme with pancreatic secretions (Dunaiff \& Schneeman, 1981; Isaakson et al. 
1982) and reduce the contact of digesta with the epithelium (Blackburn et al. 1984). If this is the case, how can a reduction in fat absorption when the viscosity of ileostomy effluent is decreased be explained? The answer to this paradox may be that although the viscosity of the gastric effluent may be increased, delaying digestion and absorption and shifting the site of absorption of the fat downstream (Jenkins et al. 1977; Schnell et al. 1985) associated with progressive dilution by increased digestive secretions (Elsenhans et al. 1984) may then alter the properties of the guar gum mixture (Edwards et al. 1987), and the amount of water held (up to $27 \mathrm{~g} / \mathrm{g}$ dry material; Stephen \& Cummings, 1979) may make the effluent quite runny compared with normal semi-solid ileostomy effluent. Several patients commented that their effluent had a more fluid consistency during the guar-gum period. Bacterial degradation of the guar gum could also reduce the viscosity of the ileostomy effluent substantially, but the contents of the ileostomy bag were not obviously offensive.

Another possibility is that the reduction in absorption could be related to the increase in lumen volume. The observation that guar gum doubled ileostomy effluent but only reduced mean transit time by $25 \%$ indicates a $50 \%$ increase in lumen volume, which could dilute complex nutrients, reduce their contact with the epithelium and also generate propulsive movements which could be responsible for the acceleration of transit. As such, our results are compatible with studies in dogs which showed that ingestion of guar gum increased lumen flow-rate by an increase in volume rather than an acceleration of transit time, and at the same time reduced the absorption of fat (Meyer \& Doty, 1988).

In summary, our results show that it is not always possible to predict what will happen to small intestinal function when guar gum is added to the diet from experiments carried out when guar gum is administered alone or with a simple dietary component such as glucose. While our findings show that guar gum will reduce nutrient absorption, the mechanisms involved are more complicated than hitherto envisaged.

\section{REFERENCES}

Adrian, J. (1976). Gums and hydrocolloids in nutrition. World Review of Nutrition and Dietetics 25, $189-216$.

Blackburn, N. A., Redfern, J. S., Jarjis, H., Holgate, A. M., Hanning, I., Scarpello, J. H. B., Johnson, I. T. \& Read, N.W. (1984). The mechanism of action of guar gum in improving glucose tolerance in man. Clinical Science 66, 329-336.

Bueno, L., Praddaude, F., Fioramonti, J. \& Ruckenbusch, Y. (1981). Effect of dietary fibre on gastrointestinal motility and jejunal transit time in dogs. Gastroenterology 80, 701-707.

Dunaiff, G. \& Schneeman, B. O. (1981). The effect of dietary fibre on the pancreatic excretory function. American Journal of Nutrition 34, $1034-1035$.

Edwards, C. A., Blackburn, N. A., Craigen, L., Davison, P., Tomlin, J., Sugden, K., Johnson, I. T. \& Read, N. W. (1987). Viscosity of food gums determined in vitro related to their hypoglycemic actions. American Journal of Clinical Nutrition 46, 72-77.

Ellis, P. R., Morris, E. R. \& Low, A. G. (1986). Guar gum: the importance of reporting data on its physicochemical properties. Diabetic Medicine 3, 490-491,

Elsenhans, B., Zenker, D., Caspary, W. F. \& Blume, R. (1984). Guaran effect on rat intestinal absorption. Gastroenterology 86, 645-653.

Evans, E. \& Miller, D. S. (1975). Bulking agents in the treatment of obesity. Nutrition and Metabolism 18, $199-203$.

Fuessl, H. S., Williams, G., Adrian, T. E. \& Bloom, S. R. (1987). Guar sprinkled on food: effect on glycaemic control, plasma lipids, and gut hormones in non-insulin dependent diabetic patients. Diabetic Medicine 4, 463-468.

Higham, S. E. \& Read, N. W. (1990). Effect of ingestion of fat on ileostomy effluent. Gut 31, 435-438.

Isaakson, G., Lundquist, I. \& Ihse, I. (1982). Effect of dietary fibre on pancreatic enzyme activity in vitro. Gastroenterology 82, 918924.

Jenkins, D. J. A., Leeds, A. R., Gasull, M. A., Cochet, B. \& Alberti, G. M. M. (1977). Decrease in postprandial insulin and glucose concentrations by guar and pectin. Annals of Internal Medicine 86, 20-23.

McNeil, N. I. (1984). The contribution of the large intestine to energy supplies in man. American Journal of Clinical Nutrition 39, 338-342.

Meyer, J. H. \& Doty, J. E. (1988). GI transit and absorption of solid food: multiple effects of guar. American Journal of Clinical Nutrition 48, 267-273. 
Read, N. W. (1986). Dietary fibre and bowel transit. Dietary Fibre Basic and Clinical Aspects, pp. 91-100 [G. V. Vahouny and D. Kritchevsky, editors]. New York and London: Plenum Press.

Sandberg, A. S., Ahderinne, R., Andersson, H., Hallgren, B. \& Hulten, L. (1983). The effect of citrus pectin on the absorption of nutrients in the small intestine. Human Nutrition: Clinical Nutrition 37C, 171-183.

Schnell, M., Pacy, J. F. \& Judd, P. A. (1985). Effect of guar gum intake on chylomicron size and composition in the rat. Proceedings of the Nutrition Society 44,17A

Smith, U. \& Holm, G. (1982). Effects of a modified guar gum preparation on glucose and lipid levels in diabetics and healthy volunteers. Atherosclerosis $45,1-10$.

Sommer, H. \& Kasper, H. (1980). The effect of dietary fibre on the pancreatic excretory function. Hepatogastroenterology 27, 477-483.

Stephen, A. M. \& Cummings, J. H. (1979). Water-holding by dietary fibre in vitro and its relationship to faecal output in man. Gut 20, 722-729.

Van de Kamer, J. H., Huinink, H. ten B. \& Weijers, H. A. (1949). Rapid determination of fat in faeces. Journal of Biological Chemistry 177, 347-355.

Varley, H. (1984). Practical Clinical Biochemistry, 5th ed. London: Heinemann. 